\title{
Erratum to: Do Crime Hot Spots Exist in Developing Countries? Evidence from India
}

\author{
David M. Mazeika1 Sumit Kumar $^{2}$
}

\section{Erratum to: J Quant Criminol DOI 10.1007/s10940-016-9280-2}

Unfortunately, the original publication of the article was published with the unwanted phrase Research Note at the end of the title. The corrected title of the article is published with this erratum.

The online version of the original article can be found under doi:10.1007/s10940-016-9280-2.

David M. Mazeika

mazeikad@tcnj.edu

1 Department of Criminology, The College of New Jersey, P.O. Box 7718, Ewing, NJ 08628-0718, USA

2 Department of Criminology and Criminal Justice, The University of Maryland, College Park, MD, USA 